\title{
A RESILIÊNCIA EM MERCADOS POPULARES: UMA ANÁLISE NO MERCADO CENTRAL DE FORTALEZA
}

\author{
THE RESILIENCE IN POPULAR MARKETS: \\ AN ANALYSIS IN THE CENTRAL MARKET OF \\ FORTALEZA
}

\section{RESUMO}

Este estudo objetivou conhecer e descrever a resiliência do Mercado Central de Fortaleza. Realizou-se uma pesquisa de inspiração etnográfica e entrevistas conversacionais com 174 atores presentes no cotidiano desse mercado, analisando, mediante as lentes da resiliência, a construção coletiva e a representação do mercado popular por seus atores. A estratégia metodológica utilizada foi a análise de similitude e a análise prototípica. A intensificação do processo de urbanização, a industrialização e a expansão do setor terciário, especialmente por meio da inserção de comércio vare-

Caio Victor caiovictor.rns@gmail.com Mestrando do Programa de PósGraduação em Administração da Universidade Estadual do Ceará. Fortaleza -CE-BR.

Felipe Gerhard felipegerhard.rns@gmail.com Doutorando do Programa de Pós-Graduação em Administração da Universidade Estadual do Ceará. Fortaleza$C E-B R$.

\section{Domingos Menezes} domingos.matos@aluno.uece.br Mestrando do Programa de PósGraduação em Administração da Universidade Estadual do Ceará. Fortaleza -CE-BR.

\section{Verónica Peñaloza} vero.pf@hotmail.com Doutora Professora do Programa de Pós-Graduação em Administração da Universidade Estadual do Ceará. Fortaleza - CE-BR. jista mais moderno, transformaram o espaço urbano de Fortaleza. Como consequência, o Mercado Central atravessa um período de crise e estagnação, referente às baixas expectativas dos entrevistados. O trabalho contribuiu para compreensão das expectativas dos comerciantes em relação ao mercado. Sabendo da importância e o valor desse patrimônio histórico cultural para a cidade, o mercado necessita de um processo de revitalização.

Palavras-chave: Mercado Central. Resiliência. Análise de Similitude. Análise Prototípica.

\begin{abstract}
This study aimed to know and describe the resilience of the Central Market of Fortaleza. A research of ethnographic inspiration and conversational interviews with 174 actors present in the daily life of this market was carried out, analyzing, through the lenses of resilience, the collective construction and representation of the popular market by its actors. The methodological strategy used was the similitude analysis and prototypical analysis. The intensification of the process of urbanization, industrialization and expansion of the tertiary sector, especially through the insertion of more modern retail trade, transformed the urban space of Fortale-
\end{abstract}


za. As a consequence, the Central Market is in a period of crisis and stagnation, referring to the low expectations of the interviewees. The work contributed to the understanding of traders' expectations regarding the market. Knowing the importance and value of this historical cultural heritage for the city, the market needs a revitalization process.

Keywords: Central Market. Resilience. Similitude Analysis. Prototypic Analysis.

\section{INTRODUÇÃO}

Novas e sugestivas formas de atrair clientes têm surgido todos os dias sob o signo de um conceito original, uma experiência de compra recente ou uma novidade mercadológica indispensável. A lógica da constante superação, deixando obsoletos conceitos até pouco tempo em voga e da transformação dos significados antigos em sentidos novos e sofisticados tem sido a tônica mercadológica atual - capaz de capitalizar, até mesmo, elementos culturais de elevada abstração (LIPOVETSKY, 2007).

A cada dia, são lançados novos produtos e tendências, assim como são suscitados novos hábitos de se relacionar, de se comportar e, principalmente, novas formas de construir a própria identidade. Utilizam-se, para isso, os infindáveis signos oferecidos pelo mercado (BELK, 1988; BAUDRILLARD, 1995; LIPOVETSKY, 2007). Diante desse cenário, seria impensável supor a existência de ambientes que não sigam a gramática das constantes inovações do mercado. É imperativo às empresas atuais a incessante adaptação aos sempre mutáveis contextos econômico-sociais no intuito de se manter vantagem competitiva e aumentar seu market share (MEDD; MARVIN, 2005; BURNARD; BHAMRA, 2011).

No entanto, existem ambientes que parecem resistir às ideologias mercadológicas de nossa época. Os mercados populares, i.e., mercados de produtos regionais, como os mercados municipais, as feiras livres e os mercados de troca são espaços que têm acompanhado o avanço e a institucionalização dos atuais templos de consumo, representados pelos modernos shopping centers, sem perder as suas raízes históricas (KINJO; IKEDA, 2005).

Embora estejam muito mais presentes no cotidiano da população menos abastada de países e regiões mais pobres, os mercados populares são frequentados por consumidores de diferentes camadas econômicas (SHERRY JUNIOR, 1990; OLAVARRIETA; FRIEDMANN, 2008; RAJAGOPAL, 2010). Seu público é multidiversificado, porquanto seja constituído por pessoas de diferentes idades, gêneros, etnias, religiões etc. (SARAIVA; CARRIERI; SOARES, 2014). A heterogeneidade de seus consumidores também se reflete nos diferentes objetivos por eles almejados ao visitar tais locais - seja para procurar um produto mais barato, seja para buscar lembranças de infância lá preservadas (GERHARD; PEÑALOZA, 2018).

Embora infindáveis modificações tenham ocorrido, suas principais tradições e características têm-se preservado. Alguns dos hábitos dos atores que constroem diariamente esses mercados persistem ao longo do tempo; a essência de valorizar aquilo que é mais simples e cotidiano tem-se mantido apesar de despontarem em culturas, épocas e contextos sociais totalmente diferentes (ALVES; RIBEIRO FILHO, 2011).

Os mercados populares, dessa forma, apresentam alto grau de resiliência; uma vez que tais ambientes não somente se apresentam de forma destoante aos sofisticados espaços urbanos de consumo, mas também por existirem desde a formação das primeiras cidades (SARAIVA; CARRIERI; SOARES, 2014). Essa resiliência tem-se apresentado, de forma decisiva, para a preservação do conceito dos mercados populares, o qual se baseia na comercialização de produtos da terra, na valorização da cultura regional, na conservação da identidade local, entre outros (ALVES; RIBEIRO FILHO, 2011).

Todavia, a concepção de resiliência não 
é a mesma para todos os mercados populares. Utilizando-se da perspectiva econômica, tipos de mercados como feiras livres e shopping centers, que apresentam uma resiliência muito maior do que os mercados públicos (PACHECO, 2012; GERHARD; PEÑALOZA, 2018), sempre procuram modificar-se para atender uma maior quantidade de indivíduos, em um movimento contrário, os mercados públicos estão enfrentando momentos de instabilidade econômica e baixo fluxo de clientes (ALVES; RIBEIRO FILHO, 2011). Apesar disso, muitos mercados públicos persistem na sociedade, modificando sua organização e incorporando novas funções de acordo com as demandas do momento vigente (HOLLING, 2001; FRANCIS; BEKERA, 2014).

Entre as diversas manifestações econômicas ligadas à cultura popular, os mercados públicos diferenciam-se por disporem de melhor infraestrutura e gestão, além de um relacionamento mais próximo com o setor público do que os demais mercados populares. Além disso, tais mercados possuem características sui generis que os permitem, enquanto espaço de trocas, persistir no tempo, ter sentido e modificar-se ao passo que cria raízes (PINTAUDI, 2006). Não obstante, a relutante presença de mercados populares no atual contexto mercadológico brasileiro não seja um fenômeno singular, poucos trabalhos foram realizados em tais contextos (e.g., CARRIERI; SARAIVA; PIMENTEL, 2008; CAVEDON, 2004; PIERRI; VALENTE, 2010; CAVEDON et al., 2011), principalmente, quando a resiliência em mercados públicos é vista por meio da ótica dos seus próprios agentes econômicos (PERDIGÃO; CARRIERI; SARAIVA, 2014).

Dessa forma, este estudo tem como objetivo analisar, por meio das lentes da resiliência, a construção coletiva e a representação do mercado popular por seus atores econômicos; explanando, além disso, suas vulnerabilidades e fortalezas para constatar como auxiliam ou prejudicam a resiliência desse ambiente. Para tal, será realizada uma pesquisa de inspiração etnográfica e entrevistas conversacionais com atores presentes no cotidiano do Mercado Central de Fortaleza.

Este trabalho está divido em quatro seções além desta introdução. Inicialmente, será apresentada uma breve síntese das origens e da evolução do conceito de resiliência, desde a sua concepção à apropriação científica do termo por diversas disciplinas. Em seguida, serão evidenciados os principais aspectos metodológicos do trabalho. Serão analisados, por conseguinte, os resultados dos dados e das informações emersas da pesquisa de campo. Por fim, apresentam-se as considerações finais do estudo, destacando-se as maiores limitações do trabalho e as sugestões para pesquisas futuras.

\section{REFERENCIAL TEÓRICO}

\subsection{RESILIÊNCIA}

Com o intuito de manter vantagem competitiva, mudança e adaptação são exigidas dos sistemas atuais como um movimento obrigatório, em resposta às flutuações ambientais (MEDD; MARVIN, 2005; BURNARD; BHAMRA, 2011). Destarte, a resiliência, em vista das adversidades que ocasionam ciclos de desenvolvimento deletérios, é recomendada a todos os agentes presentes no mercado; porquanto se caracteriza como mecanismo capaz de habilitar indivíduos, organizações ou sistemas a adaptarem-se a mudanças advindas do ambiente externo (BURNARD; BHAMRA, 2011; OZUDURU; VAROL; ERCOSKUN, 2014; PETRESCU; BHATLI, 2013).

Ao longo das últimas décadas, os trabalhos voltados ao aprofundamento de estudos referentes à resiliência vêm ganhando notoriedade, tanto no meio acadêmico, quanto para as políticas públicas (MEDD; MARVIN, 2005; SOUMAGNE et al., 2009; STUMPP, 2013). O conceito de resiliência, originalmente cunhado nas ciências naturais, vem sofrendo adaptações teóricas para abranger um escopo de pesquisa cada vez maior. Embora tenha ganhado maiores proporções 
especialmente nas ciências médicas e comportamentais (SMITH et al., 2008), o conceito pôde transitar nas mais distintas ciências, auxiliando, sobremaneira, as disciplinas e as instituições a enfrentar os problemas teóricos e práticos que lhes são próprios.

Não obstante seja uma qualidade importante que faculta a indivíduos e sistemas de proteção contra a adversidade, não há consenso quanto às definições operacionais existentes, uma vez que a literatura concernente ao tema ainda permanece incerta em relação ao acesso da resiliência em diferentes contextos históricos, sociais e culturais (HERRMAN et al., 2011; BUENO, 2012; LEE et al., 2013).

A qualidade de ser resiliente indica a capacidade de se manter ou atingir um equilíbrio dinâmico em harmonia com a reorganização advinda da adaptação às adversidades enfrentadas (HOLLING, 1973; PATON; SMITH; VIOLANTI, 2000; HAMEL; VALIKANGAS, 2003; WALKER et al., 2006; LUTHANS et al., 2006; RUTTER, 2006; BRIGUGLIO et al., 2009; SOUMAGNE et al., 2009; HERRMAN et al., 2011; LEE et al., 2013).No que concerne aos sistemas de varejo urbano, i.e., aglomerados de negócios interdependentes que compartilham o mesmo espaço físico, infraestrutura e imagem (MEDD; MARVIN, 2005; SOUMAGNE et al., 2009), ainda não há consenso quanto à definição ideal de resiliência para análises empíricas (HERRMAN et al., 2011; BUENO, 2012). Contudo, um movimento judicioso a tais sistemas é o de autoanálise contínua, cuja função principal é a ciência das vulnerabilidades e fortalezas que permitem a sua sobrevivência (HOLLING, 2001; FRANCIS; BEKERA, 2014). O exame dos principais pontos fracos e fortes de um sistema de varejo urbano, dessa forma, coadjuvaria a construção da ideia de resiliência.

Nas Ciências Sociais Aplicadas, o termo resiliência passou a se reportar não somente a indivíduos, mas a grupos, organizações e sistemas econômicos. Contudo, independentemente do objeto de análise, a resiliência está associada à ideia de se suportar pressões, cri- ses e adversidades (YUNES, 2003). Embora, nos últimos anos, as ciências econômicas tenham-se apropriado grandemente do conceito para embasar análises de mercados, setores e sistemas econômicos (HERRMAN et al., 2011; STUMPP, 2013), foi, especialmente, nas ciências médicas e comportamentais que a resiliência ganhou maiores proporções (SMITH et al., 2008).

Não obstante a relevância que o tema alcançou ao longo dos últimos anos (STUMPP, 2013), ainda é pequena a contribuição dos trabalhos nacionais voltados ao exame da resiliência nas ciências sociais aplicadas. Os estudos nacionais se concentram, fortemente, na área de recursos humanos, tendo como objeto de análise os indivíduos nas organizações; passando ao largo de questões relacionadas à perspectiva urbana e social (e.g., CARVALHO et al., 2011; GOMIDE JÚNIOR; SILVESTRIN; OLIVEIRA, 2015; IRIGARAY; PAIVA; GOLDSCHMIDT, 2017). Abaixo, encontram-se as principais forças de resiliência dos sistemas de varejo urbanos (tabela 1), divididas em três esferas: política, econômica e inovação. Elucidam-se aqui os principais pontos para se lograr a capacidade de adaptação, flexibilidade ou manter-se em equilíbrio diante de situações adversas. 
Tabela 1 - Níveis e medidas de resiliência em sistemas de varejo

\begin{tabular}{|c|c|}
\hline Nível Governamental & $\begin{array}{l}\text { - Modificar positivamente a imagem do ambiente. } \\
\text { - Melhorar as estradas de acesso local. } \\
\text { - Intensificar a segurança local; } \\
\text { - Expandir e reforma estrutural (por exemplo, calçadas, espaço interno, } \\
\text { estacionamento, stands). } \\
\text { - Melhorar as condições de higiene. } \\
\text { - Promover educação financeira e empresarial. } \\
\text { - Possibilitar a expansão turística. } \\
\text { - Limitar a inserção de grandes empresas nas proximidades. }\end{array}$ \\
\hline Nível Sistêmico & $\begin{array}{l}\text { - Proporcionar o crescimento econômico e diversidade. } \\
\text { - Destacar valores culturais, entretenimento e lazer. } \\
\text { - Planejar em longo prazo. } \\
\text { - Fazer liderança forte e responsável. } \\
\text { - Criar e divulgar os festivais. } \\
\text { - Ter preocupação estética. } \\
\end{array}$ \\
\hline Nível Individual & $\begin{array}{l}\text { - Propiciar a aprendizagem. } \\
\text { - Estabelecer relações interpessoais sólidas com clientes e concorrentes. } \\
\text { - Ter força de valor e vantagens competitivas. } \\
\text { - Desenvolver estratégias competitivas (negociação, promoção, desconto, } \\
\text { catálogos com produtos). } \\
\text { - Auto-organizar. } \\
\text { - Focar na inovação. }\end{array}$ \\
\hline
\end{tabular}

Fonte: adaptado de Medd e Marvin (2005), Soumagne et al. (2009), Ozuduru, Varol, e Erscoskun (2014), Petrescu e Bhatli (2013) e Erkip, Kizilgun e Akinci (2013).

\subsection{MERCADOS POPULARES}

Os mercados populares se destacam por dispor de um grande potencial cultural, econômico e democrático. Desde a Antiguidade, o mercado público não se caracteriza apenas por ser um espaço comercial comum, muito além disso, manifesta a cultura legítima da região, cenário de grande diversidade, dos costumes e comportamentos de uma comunidade identificados na troca de mercadorias, no consumo e na produção de artigos locais e artesanais (SARAIVA; CARRIERI; SOARES, 2014).

Os mercados públicos no Brasil constituem uma modalidade de mercado varejista coberto, de periodicidade diária, organizados como serviço de utilidade pública pelo próprio município e direcionado para a distribuição local e turística de produtos que vão desde gêneros alimentícios até produtos artesanais sofisticados (SIQUEIRA, 1993; DANTAS, 1996). Dispor dessa essência cultural é o que possibilita distinguir o mercado público de outros estabelecimentos comerciais, e.g., shopping centers, sendo imprescindível que ele possua um espaço diferenciado que possibilite essa qualidade transcendental de conservação e propagação da cultura regional e a preservação da identidade local (PIMENTEL et al., 2011).

No entanto, se analisarmos pela perspectiva do consumo, os mercados populares estão perdendo seu espaço (ALVES; RIBEIRO FILHO, 2011). Mesmo oferecendo uma imensa diversidade de produtos ao longo dos anos, não se evitou que os mercados atravessassem um período de crise (ALVES; RIBEIRO FILHO, 2011). O ideário progressista de consumo das cidades brasileiras tem contribuído para a destruição da identidade dos mercados públicos. Há uma corrente de maior valorização do novo em detrimento do velho, acarretando, destarte, o parcial esquecimento e a desvalorização pela população dos mercados populares - os quais passam a simbolizar fragmentos do passado (CAVEDON, 2004). 
Como consequência, a maior ou menor presença de formas comerciais mais rústicas, como as feiras livres e os próprios mercados municipais ou mais sofisticados, como supermercados e shopping centers, indicam uma estreita relação com a evolução das cidades. Atualmente, o consumo massificado tem proporcionado o crescimento dessas organizações de comércios, que estão voltados para a venda em maior quantidade e preços mais baixos, caracterizando-as como concorrentes dos mercados populares.

Nesse hiato, que existe na perspectiva do consumo massificado das sociedades hodiernas, encontra-se o mercado popular. Com a finalidade de garantir a continuidade das atividades comerciais nesses estabelecimentos, a busca pela diversificação dos produtos comercializados, distanciando-se da oferta de produtos agrícolas, tornou-se algo fundamental para a sua resiliência (HOLLING, 2001; BURNARD; BHAMRAA, 2011; FRANCIS; BEKERA, 2014). Dessa maneira, a atual diversidade encontrada nos mercados públicos é o efeito de uma fuga encontrada pelos comerciantes para assegurar a lucratividade e a existência de suas lojas (ALVES; RIBEIRO FILHO, 2011).

Mesmo com a baixa resiliência em comparação com as feiras livres (GERHARD; PEÑALOZA, 2018) e os shopping centers (PACHECO, 2012), os mercados públicos passaram por várias transformações e começaram a incorporar novas funções de acordo com as demandas do momento vigente. Desse modo, os mercados públicos remanescentes permaneceram pela importância que possuem para a memória e a cultura da cidade, o que explica sua forte dependência do setor público (CAVEDON, 2004).

Apenas uma porção dos mercados públicos atualmente é capaz de harmonizar atributos tidos como tracionais e da modernidade. Mantendo sua importância enquanto configuração comercial, e, por conseguinte, sustenta um aspecto de antagonismo na estrutura da cidade, ao agrupar diferentes tipos de produtos e pela nostalgia que o ambiente transporta (KINJO; IKEDA, 2005). No presente, os mercados populares têm voltado seus esforços para a atração turística. Assim, localizados, principalmente, em centros de comércio urbanos, os mercados públicos compõem o patrimônio históricos das cidades, assumindo duas funções essenciais para a sociedade, tanto estética quanto comercial (PIMENTEL et al., 2011).

A atmosfera dos mercados populares configura-se como alegre e festiva, local de encontro, convívio e conversa amiga, fruto da confluência de tradições e hábitos da cultura local. Ao introduzir-se nesse local, é importante transcender a simples racionalidade financeira e recrear-se com a riqueza histórica, estética e simbólica que o lugar possui para o imaginário da sociedade. Transgredindo as barreiras do consumo em massa, esse micromundo congrega, em um momento presente, as lembranças históricas e culturais de um povo.

A geração de pesquisas com essa característica, em se tratando das dimensões de um país como o Brasil, ainda se configura como inexpressiva, especialmente, com relação a determinadas organizações cujas interfaces remontam aos aspectos históricos e culturais peculiares de uma dada localidade ou região (CAVEDON, 2004).

\section{PROCEDIMENTOS ME- TODOLÓGICOS}

Com o intuito de analisar a construção coletiva das representações sociais do mercado central de Fortaleza à luz do conceito de resiliência, foi realizado um estudo de natureza qualitativa de caráter básico ou genérico (MERRIAM, 2009). A pesquisa, de fim exploratória, ademais, é classificada como trabalho de campo, uma vez que as investigações empíricas foram realizadas no local de ocorrência dos fenômenos estudados (VERGARA, 2005). Para as análises, foram utilizadas a observação sistemática (SPRADLEY, 1980; BOGDAN; TAYLOR, 1975) e duas técnicas lexicométricas: Análise Prototípica e Análise de Similitude. 


\subsection{AMBIENTE DE PESQUISA}

O Mercado Central de Fortaleza se enquadra como uma organização local, cuja cultura organizacional apresenta características da cultura fortalezense e cearense, sendo considerada como uns dos principais pontos turísticos da capital. O mercado é compreendido como um patrimônio histórico e, como tal, deve ser preservado pela população, uma vez que conserva toda a memória e tradição de um povo.

O mercado central de Fortaleza vem passando por modificações e reformas estruturais com o intuito de enfrentar as ameaças decorrentes da instalação de grandes complexos de mercados informais nas proximidades. Do mesmo modo, as ações públicas voltadas à melhoria do mercado têm como intuito inseri-lo na rota turística do Estado, destacando-o como importante centro de divulgação da arte e cultura local.

Tais acontecimentos são importantes para ressaltar as capacidades de adaptação e enfrentamento do mercado em face das mudanças ocorridas no ambiente. Assim, o processo atual de mudança caracteriza-se como um momento oportuno para a análise da resiliência do local. Quanto às suas instalações atuais, o mercado conta com uma estrutura de três andares e um subsolo interligado por passarelas e um elevador. São, ao todo, 559 boxes, 70 quiosques e cinco restaurantes, em que são oferecidos produtos com as mais diversificadas tonalidades da cultura local.

\subsection{PROCEDIMENTO}

Após a obtenção dos dados pela evocação livre, foram submetidos a uma estratégia metodológica que envolveu o uso de duas técnicas lexicométricas. A primeira técnica, desenvolvida por Pierre Vergès, foi a Análise Prototípica que tem como objetivo identificar a estrutura base da representação social, por meio do cruzamento das frequências das palavras obtidas na evocação com as suas respectivas ordens (PEREIRA, 2001). A interseção das duas coordenadas gera um gráfico de contingência constituído por quatro zonas que permitem constatar o que é central e aquilo que é periférico nas representações sociais. Nesse formato cartesiano, consideram-se as evocações do núcleo central, ou primeiro quadrante, as evocações que obtiveram maior frequência e menor, já as evocações periféricas, as de menor frequência e de maior ordem (WACHELKE; WOLTER, 2011).

A Análise de Similitude, a segunda técnica lexicométrica utilizada, tem sua constituição fundada na teoria dos grafos. Amplamente empregada nas descrições das representações sociais, a teoria dos grafos tem como objetivo estudar a proximidade e as relações entre os elementos de um conjunto de conceitos (MARCHAND; RATINAUD, 2012). As evocações foram agrupadas e, posteriormente, relacionadas por meio de um índice de semelhança, chamando de coocorrência (VERGÈS; BOURICHE, 2001). Mediante esse índice, será possível estruturar o processamento, desde a informação na mente humana até a representação social do fenômeno estudado (PEREIRA, 2001).

A aplicação combinada dessas duas técnicas nos permite a realização, tanto de uma análise de similitude, quanto de uma análise confirmatória dos núcleos centrais e periféricos propostos anteriormente na análise prototípica, colocando, em destaque, a organização das evocações e permitindo identificar-se uma estruturação entre eles (PEREIRA, 2001). O tratamento dos dados mediante as duas análises supracitadas fora executado no software IRAMUTEQ (Interface de $R$ pour lês Analyses Multidimensionnelles de Texteset de Questionnaires), programa pertencente ao software $\mathrm{R}$ que permite realizar análises estatísticas em corpus textuais.

\subsection{CORPUS DE PESQUISA}

Participaram da pesquisa 174 vendedores do Mercado Central de Fortaleza. Inicialmente, solicitou-se aos entrevistados que respondessem, baseando-se na própria opinião, se a feira cresceu, diminuiu ou se manteve constante nos 
últimos anos. As entrevistas duravam cerca de sete minutos; o que resulta em um total de mais de 25 horas em campo. Logo após, foram requisitadas aos feirantes as principais razões pelas quais acreditavam nos cenários apontados. Excluíram-se as palavras ou expressões que não possuíam sentido semântico próximo aos grupos formados.

Foram realizadas entrevistas estruturadas de curta duração com 174 vendedores do mercado central, aos quais foram realizadas, além das questões de caráter sociodemográfico, as seguintes perguntas: "Nos últimos anos, o mercado vem crescendo, diminuindo, ou permanece constante? Por quais motivos?"; "E para os próximos anos, a tendência será crescer, diminuir ou permanecer constante?".

Quanto ao desenho das entrevistas, uma ressalva deve ser feita. Embora se delimitasse as respostas dos entrevistados às perguntas iniciais, os pesquisadores não tolhiam o discurso dos respondentes, possibilitando a coleta de informações adicionais sobre o processo de resiliência do mercado. Em geral, os entrevistados não se detinham na explicação das razões apontadas, o que levava as entrevistas a se estenderem por cerca de oito a dez minutos, permitindo-lhes discorrer com maior profundidade sobre percepções e opiniões que nutriam a respeito do mercado.

Dessa forma, embora fossem levantadas palavras ou expressões para a criação do quadro semântico das opiniões dos entrevistados, foi possível aferir impressões mais profundas dos respondentes a respeito do local. Do mesmo modo, entre os meses de janeiro a abril de 2019 , os pesquisadores passaram a frequentar, diariamente, o local com o intuito de coletar material mediante a observação e o convívio com as personagens do mercado.

\section{ANÁLISE DOS RESULTADOS}

\subsection{ANÁLISE PROTOTÍPICA}

Para a realização da análise prototípica, foi necessário realizar um tratamento pré- vio das evocações. Inicialmente, foi realizado o agrupamento das palavras de acordo com o radical ou a classe gramatical. Esse processo se denomina lematização. O motivo para se realizar esse procedimento é para evitar ambiguidades e divergências do processo de categorização das evocações, assim, a pesquisa pode-se tornar replicável mais facilmente (WACHELKE; WOLTER, 2011). Após a lematização, devido à quantidade de palavras ou expressões semelhantes, optou-se por um tratamento das respostas mais preciso. Dessa forma, foi necessário realizar o agrupamento semântico juntando palavras com significados semelhantes e deixando a palavra com maior frequência na análise. Esse processo tem função de melhorar a representação das evocações e deixar a análise mais concisa.

Desconsiderando-se os casos omissos, foram auferidas 360 palavras ou expressões, possuindo frequência média de 3,27. Após o processo de lematização e agrupamento semântico, foram selecionadas as palavras com frequência maior que 2, restando para a análise 290 evocações, alcançando $80,5 \%$ do tamanho da amostra. A nova frequência média aumentou para 7,75, o que sugere maior credibilidade na representação dos vendedores, pois restaram apenas as palavras mais importantes para a análise.

Em relação ao gráfico da análise prototípica (figura 1), o ponto de corte para a coordenada da frequência de palavras foi de 7,73 , ou seja, todas as palavras com frequência igual ou superior a esse número se mantiveram nos quadrantes superiores (I e II). As palavras com frequência maior que o ponto de corte nos quadrantes superiores correspondem a $73,1 \%$ do total de evocações; podendo-se inferir que os núcleos centrais (I) e o primeiro periférico (II) estão compactados e conseguindo retratar, com maior fidedignidade, o pensamento social dos vendedores neste contexto. Quanto ao critério do ponto de corte para a ordem média de evocações (OME), foi utilizada a média das palavras escolhidas para a análise, com valor igual a 1,74 . Os quadrantes I e III obtiveram menor OME, indicando que essas palavras fo- 
ram as primeiras que vieram na mente dos respondentes, ao passo que os quadrantes II e IV obtiveram maior OME, sendo denominados primeiro e segundo periféricos.

Figura 1 - Gráfico de Contingência - Análise Prototípica dos vendedores do Mercado Central

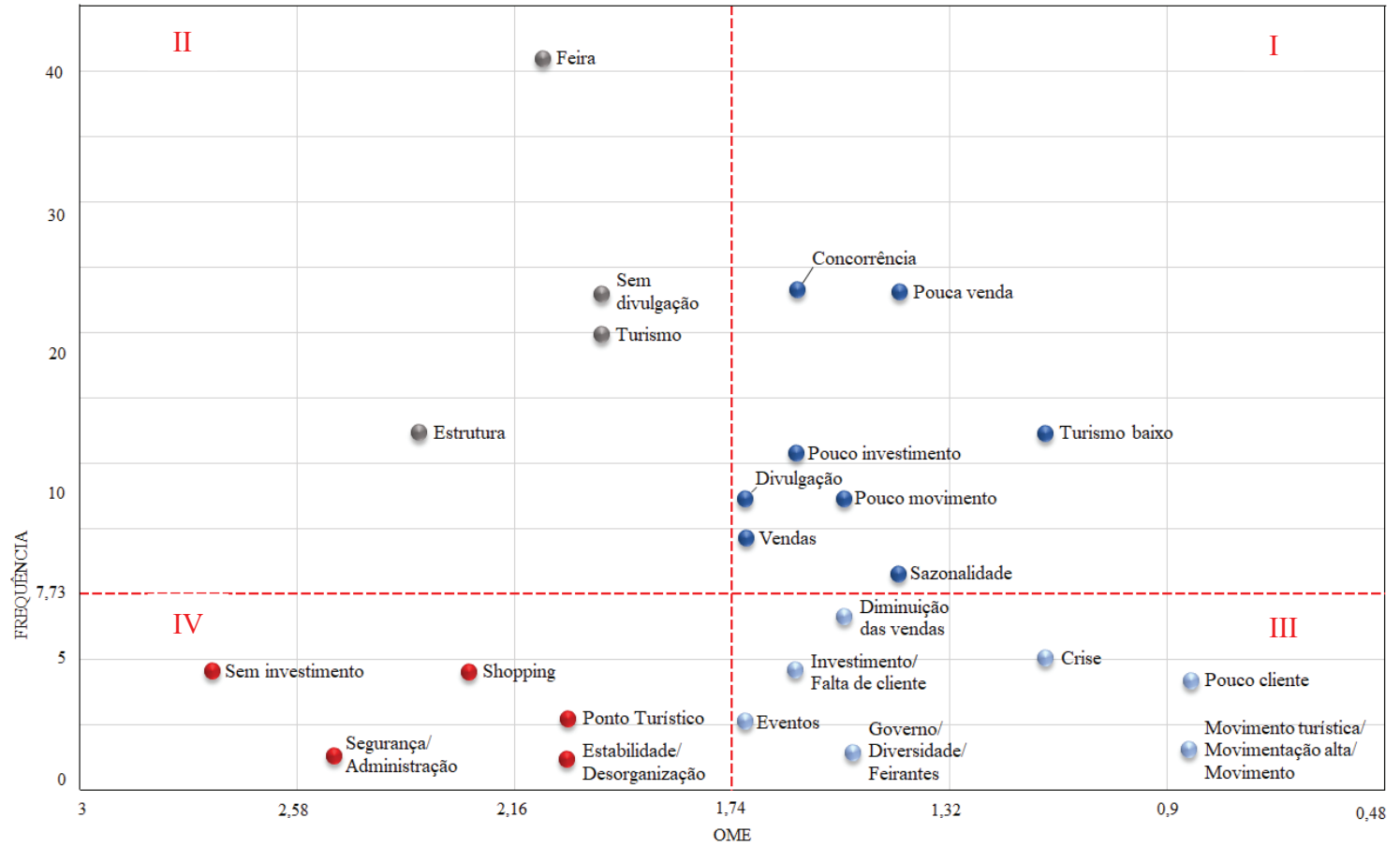

Fonte: elaboração própria.

O quadrante I no gráfico representa as palavras com menor OME e maior frequência, isso implica que essas evocações apresentam grande potencialidade para se tornarem os núcleos centrais da representação dos vendedores do Mercado Central. Nesse quadrante, podese observar que as evocações "Pouca Venda" possuem maior centralidade, o que indica que a maioria dos vendedores estão com problemas em relação à comercialização de seus produtos. As outras palavras ou expressões citadas foram "Concorrência", "Turismo baixo", "Pouco Investimento", "Divulgação", "Pouco movimento", "Vendas" e "Sazonalidade".

Os quadrantes periféricos (II e III) são constituídos de elementos que são secundários na análise, mas são importantes para a representação social. Ou seja, evocações nesses quadrantes retratam, de maneira mais específica, os indivíduos entrevistados e não podem ser generalizadas (ABRIC, 2003). Nesses quadrantes, pode-se destacar a palavra "Feira" que possui a maior frequência da análise (41 evocações) e está relativamente próxima dos núcleos centrais. Outras palavras em destaque são: "Sem divulgação", "Turismo", "Estrutura", "Diminuição das vendas", "Crise" e "Pouco cliente".

Para finalizar, o quadrante IV é representado por palavras que fazem parte da construção do espaço do Mercado Central, porém são pouco importantes no campo da representação, devido a seu OME e sua baixa frequência. Geralmente, nesse quadrante, as representações são baseadas em aspectos específicos dos indivíduos (WACHELKE; WOLTER, 2011).

A análise prototípica serve de embasamento para se ter consciência dos núcleos centrais e periféricos e quais evocações são mais importantes de serem analisados. Sua função é relatar a hipótese de centralidade das palavras; no entanto, somente essa técnica não sustenta suficientemente uma representação social 
(ABRIC, 2003), por isso as evocações foram analisadas novamente; contudo, agora, mediante a análise de similitude.

\subsection{ANÁLISE DE SIMILITUDE}

Para realizar a análise de similitude (figura 2), achou-se necessária a divisão dos indivíduos em três grupos de acordo com a primeira pergunta do questionário. "Nos últimos anos, o mercado vem crescendo, diminuindo, ou permanece constante?" Os vendedores que respondessem que o mercado cresceu foram agrupados no Grupo 1; aqueles que responderam que diminuiu foram agrupados no Grupo 2 , e, por fim, aqueles que responderam que o mercado se manteve constante formaram o Grupo 3. Desse modo, a representação de cada grupo ficou mais bem ser visualizada e compreendida.

Figura 2 - Análise de Similitude dos vendedores do Mercado Central

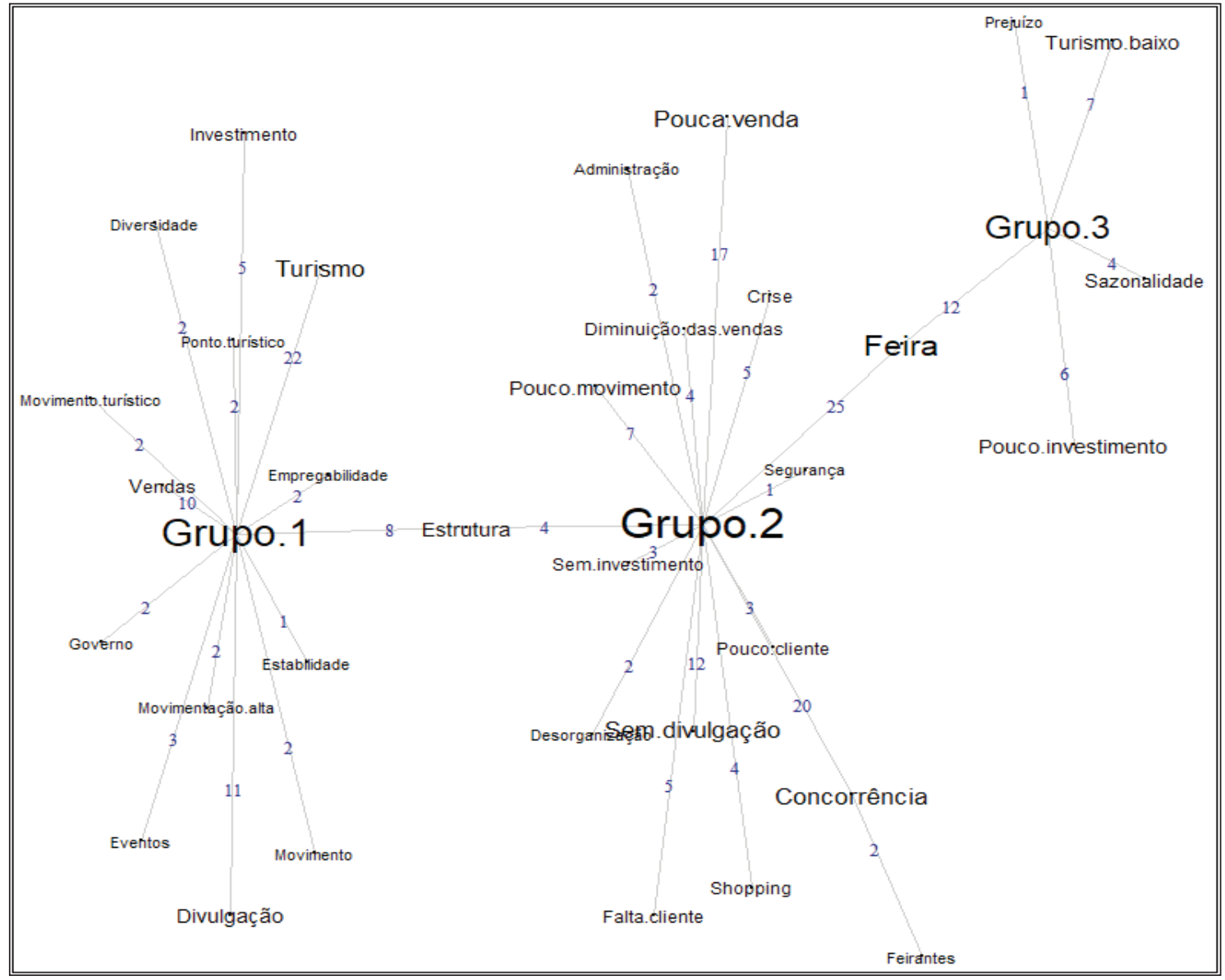

Fonte: elaboração própria.

O grupo 1 foi constituído por 59 vendedores, o grupo 2 por 70 vendedores e o grupo 3 por 45 vendedores. Além de demonstrar a divergência nas representações entre grupos, bem como a heterogeneidade presente neles, apenas 59 pessoas viram motivos para o crescimento do mercado, enquanto o restante, 115 , não acre- ditam que o mercado possa, de fato, melhorar.

Grupo 1- destacam-se, neste grupo, os motivos pelo quais os indivíduos creem que o mercado vem crescendo. Entre eles, podemos ressaltar Turismo, Divulgação, Vendas, Estrutura e Investimento. Ao comparar as evocações obtidas aqui com a análise prototípica (figura 
1), somente as evocações Divulgação e Vendas estão representadas como núcleos centrais, enquanto o restante se encontra nos quadrantes periféricos. Isso demonstra que os motivos positivos não refletem, com fidelidade, a representação dos vendedores do mercado central.

Apenas uma palavra faz a ligação entre $o$ grupo 1 e 2, "Estrutura". Elucidada por ambos os grupos; porém, com significados distintos. $\mathrm{O}$ grupo 1 vê a estrutura como um fator positivo para o crescimento do mercado; enquanto comerciantes do grupo 2 afirmam que a estrutura deixa a desejar e impacta, negativamente, as vendas. Essa distinção só foi possível pelas conversas com os vendedores, já que o programa não faz a distinção entre significado positivo ou negativo da palavra. Outras evocações próximas se destacaram, sendo elas: "Sem investimento" e "Desorganização", criando uma ideia de problemas estruturais no ambiente estudado.

Grupo 2 - constitui o maior grupo dessa análise, porém é representado por fatores que representam a diminuição do mercado. Os motivos que se destacam aqui são Pouca Venda, Concorrência, Pouco movimento, Sem divulgação, Pouco cliente e Shopping. Novamente comparando com a análise prototípica (figura 1), esse grupo possui a maior quantidade de evocações em todos os quadrantes, isso demonstra que ele representa, com maior fidelidade, o momento atual do mercado central.

Grupo 3 - constituído pelo menor número de evocações; esse grupo acredita que o mercado se manteve constante nos últimos anos. As palavras que se destacam aqui são Feira, Turismo baixo, Pouco investimento e Sazonalidade. Esse grupo possui três núcleos centrais e um núcleo periférico, segundo a análise prototípica (figura 1). Molda-se, então, como mais um importante grupo de fatores que pode retratar a representação social vivida pelos vendedores do mercado central.

A ligação entre os dois últimos grupos aconteceu pela evocação "Feira". Isso se torna bastante representativo, devido ao fato de esses dois grupos possuírem expectativas negativas quanto ao crescimento do mercado, inferindo que a feira foi um dos principais fatores pela diminuição das vendas. Essa evocação foi citada apenas por comerciantes do grupo 2 e 3 , que reclamaram da concorrência com os feirantes nos últimos anos.

Apresentados os núcleos centrais e periféricos anteriormente auferidos pela análise prototípica, confirmados e agrupados de acordo com seus respectivos grupos de vendedores pela análise de similitude, foram realizadas discussões articulando-se os achados encontrados na pesquisa - apresentadas na seção subsequente.

\section{DISCUSSÃO}

Após quatro meses de visitação diária, observação e convívio com os personagens do campo, foi possível concluir que o mercado de Fortaleza possui diversas contradições. Aproximadamente, dois terços dos comerciantes entrevistados não veem nenhuma expectativa de crescimento para suas lojas ou melhoria referente ao mercado central. Os mercados populares estão perdendo seu espaço (ALVES; RIBEIRO FILHO, 2011). Um dos núcleos centrais da representação dos comerciantes foi a evocação "Pouca venda", retratando o momento enfrentado pelos varejistas desse mercado. Segundo um dos comerciantes entrevistados: "O mercado não cresceu, porque nem o número de clientes, o volume de vendas ou o faturamento aumentaram, apenas inchamos". O que vem acarretando a diminuição das vendas é, principalmente, a concorrência de grandes comércios locais e conglomerados de negócios informais que se instalaram nas cercanias do mercado; processo que já perdura cerca de cinco anos.

Entre esses grandes conglomerados informais, os vendedores destacam a feira livre. Situada próxima ao mercado, a "Feira" foi a evocação mais citada pelos comerciantes, demonstrando ser um problema na diminuição das vendas. Os mercados populares e as feiras livres cresceram em um movimento diacrônico, mas sem perder os laços históricos. No entanto, o mercado popular não apresenta a mesma resiliência que as feiras livres, o que acarreta, na 
visão dos comerciantes, o principal fator do encolhimento das vendas, já que o mercado não se adaptou tão bem ao ambiente econômico atual.

Para alguns entrevistados, a feira ficou com a venda de atacado enquanto o mercado ficou com a venda varejista. Esse fenômeno mudou o foco do mercado à venda artesanal, pois a feira extinguiu a venda em grande quantidade associando a representação do mercado público a outro fator de destaque: a "Concorrência". "A concorrência é desleal porque os feirantes não precisam pagar taxas, empregados, água, luz e outros tributos. Também não assinam a carteira dos funcionários e não pagam aluguel" - comenta um comerciante. Segundo muitos vendedores, a feira próxima ao mercado dificulta a vinda dos turistas, porque a multidão de feirantes atrapalha o trânsito local, polui, visualmente, o ambiente e traz uma sensação de perigo.

Voltando à perspectiva do consumo, podemos explanar que o Mercado Central, no momento presente, encontra-se em uma armadilha da resiliência. Basicamente, essa armadilha é constituída por algumas contradições presentes no próprio mercado central de Fortaleza. Essas contradições foram elucidadas, baseando-se nos principais concorrentes dos mercados populares, shopping centers e feiras livres. Dessa maneira, o mercado em destaque não é (1) tão sofisticado quanto um shopping centernem tão rústico como uma feira livre; mercado não aparenta ser (2) tão turístico como deveria, mas também não é tão local ou regional como os demais mercados municipais ou feiras livres. E, por fim, o mercado não se caracteriza como (3) comercial ou artesanal, ou seja, não comercializa em grandes quantidades, mas também não comercializa produtos eminentemente artísticos. Isso acontece devido às vulnerabilidades do mercado central; ou seja, devido à sua carga histórica e cultural para a região, os seus produtos são limitados a um pequeno nicho, principalmente turístico, dificultando sua adaptação às novas demandas da sociedade; como ocorre em mercados populares em outros contextos socioeconômicos (ver: HOLLING, 2001; BURNARD; BHAMRAA, 2011; FRANCIS; BEKERA, 2014).
De acordo com a percepção dos próprios entrevistados, pode-se indicar que o Mercado Central tem passado por uma série de mudanças ao longo dos últimos anos; mas ainda menor se compararmos com as feiras e os shopping centers. A resistência do Mercado Central em se adaptar às variações do contexto socioeconômico local - para atender às demandas de consumo da sociedade - pode ser explicada pela forte relação estabelecida com a cidade; sendo considerado, inclusive, patrimônio histórico e símbolo do município. Como consequência, esse centro comercial secular se encontra preso em uma construção sociocultural que dificulta a própria resiliência. Outro indicador para esse fenômeno pode ser a forte dependência do Estado, já que o mercado necessita demais da intervenção governamental para melhorar o desempenho das vendas. Como exemplo, alguns vendedores relacionam a quantidade de vendas com os eventos promovidos pelo Governo. Os novos empreendimentos voltados para o turismo são uma esperança para os vendedores, como também a reforma de antigos pontos turísticos, como o Centro Cultural Dragão do Mar, também contribui para a esperança de melhoria. Para outros entrevistados, falta uma liderança (política ou não) que altere o provável destino de decadência do mercado.

O mercado atualmente tem, no turismo, sua principal atividade. Isso se deve aos contornos da sua própria resiliência, que, buscando sobreviver, migrou de um simples mercado hortifruti e artesanal para o nicho turístico (HOLLING, 2001; BURNARD; BHAMRAA, 2011; FRANCIS; BEKERA, 2014). No entanto, o mercado central se encontra subordinado à atividade turística. Nessa discussão, podemse mencionar as evocações "Turismo baixo" e "Sazonalidade" que foram núcleos centrais da representação social desses vendedores. Ao depender primordialmente do turismo, esses vendedores estão à mercê da sazonalidade e das vendas em menores quantidades. As palavras de um comerciante podem clarear esse pensamento: "Aqui, os meses de janeiro e julho eram conhecidos como os meses de férias, 
em que o movimento era intenso e incessante. Hoje não há mais esses períodos. O movimento caiu muito". O entrevistado complementa destacando uma provável baixa percepção de valor dos clientes locais: "Além disso, as pessoas não entendem que há esses custos vinculados ao preço final do produto, o que encarece muito. [...] Mesmo nos períodos de sazonalidade, o movimento de clientes está bem menor do que alguns anos atrás".

Quanto à divulgação do mercado, observa-se uma divergência de opiniões. Cerca de metade dos comerciantes, representados pelos grupos 2 e 3, reclamam da falta de divulgação, enquanto o restante, representados pelo grupo 1 , considera a divulgação como um aspecto positivo de resiliência do local. Outro fator importante de ser citado foi a questão da estrutura do mercado. Possuindo essa nova estrutura construída em 1998, o prédio sofreu diversas reclamações durante as entrevistas, principalmente, daqueles que possuem ótimas expectativas em relação ao mercado.

Por fim, retomando a perspectiva da resiliência e do consumo, muitos vendedores realizaram uma autocrítica em razão das suas baixas vendas, atribuindo a culpa à própria mercadoria, que, segundo eles, não atrai consumidores. As palavras de um comerciante deixam claro que os produtos vendidos aqui não acompanharam o movimento do consumo da sociedade, ele explica: "As coisas do mercado são muito antigas. São do tempo do Faraó". Se realizarmos a analogia, entende-se que o comerciante reclama que o motivo de não vender tanto quanto à feira ou aos grandes centros comerciais, decorre porque o tipo de produto vendido não está em sincronia com o consumo da sociedade atual. Outro comerciante esclarece: "Qual pessoa vai andar até aqui para comprar um produto antigo? Se turista não vier comprar, ninguém mais compra". Essa afirmação demonstra o que já foi discutido anteriormente, o mercado está preso em um hiato comercial, dependendo, principalmente, do movimento turístico para sobreviver. Desse modo, os comerciantes do mercado demonstraram dificuldades em adaptarem-se ao ritmo mercadológico dos outros centros comerciais. (MEDD; MARVIN, 2005; BURNARD; BHAMRA, 2011).

\section{CONSIDERAÇÕES FINAIS}

A intensificação do processo de urbanização, a industrialização e a expansão do setor terciário, especialmente por meio da inserção de vários tipos de comércio varejista mais moderno, transformaram o espaço urbano de Fortaleza. Como consequência, o Mercado Central atravessa um período de crise e estagnação, referente às baixas expectativas dos entrevistados elucidadas pela investigação realizada.

Na presença de novas exigências do consumo moderno, a simplicidade e o apego ao aspecto histórico cultural dos mercados tradicionais parecem ameaçar a sua sobrevivência. No entanto, esse espaço possui sua complexidade, e deve-se observar a sua importância como impulsionador da cultura e história local. Por isso, esse ambiente busca resistir às ideologias mercadológicas de nossa época. $\mathrm{O}$ mercado central tem acompanhado o avanço e a institucionalização dos grandes centros comerciais, buscado adaptar-se às mudanças mercadológicas de nossa época, porém, sem perder as suas raízes históricas.

O universo do mercado central não se limita à execução de transações comerciais, nesse local, as tradições locais são reproduzidas, valorizadas e integram toda a cultura secular de um povo. Perante os modelos econômicos incentivadores de exclusão social, o mercado tradicional concebe muitas oportunidades de trabalho e sobrevivência de várias famílias. Em virtude disso, o mercado possui, como prática comercial, o artesanato em escala, caracterizando-se, muitas vezes, como uma economia de subsistência, devido ao baixo lucro dos negócios se compararmos com os shopping centers, por exemplo.

O trabalho foi decisivo na compreensão das expectativas dos comerciantes em relação ao mercado. Foi possível entender que, embora o mercado tenha-se modificado e revitalizado diversas vezes ao longo dos anos, o momento pa- 
rece ser mais uma vez de arrocho e decadência. Esse ciclo de readaptações é importante para o mercado organizar suas atividades em direção a públicos específicos, mas sem perder o valor histórico que o caracteriza como um importante espaço de preservação da identidade local.

Sabendo da importância e o valor deste patrimônio histórico cultural para a cidade, o mercado necessita passar por um processo de revitalização, sendo aqui elucidadas algumas contribuições gerenciais: reformas em sua estrutura, desde o acesso do mercado a ampliação do estacionamento; mais políticas públicas e eventos governamentais para atrair turistas; tornar a administração do mercado mais presente, como também manter um diálogo mais constante com os comerciantes; uniformização dos preços das lojas, como também a organização dos horários de início e fim de expediente. $\mathrm{Na}$ perspectiva histórico-cultural, criação de um museu dentro do estabelecimento; instalação de atividades como uma galeria de arte, espaços para oficinas, exposições e apresentações artísticas. Fundamentado nessa revitalização, o Mercado Central de Fortaleza adquirirá seu poder cultural, histórico e turístico novamente.

Essa investigação sobre o Mercado Central de Fortaleza pode servir como uma "lente de aumento" na busca por resoluções de problemas em setores comerciais que estão sendo esquecidos gradualmente. Novas pesquisas sobre mercados populares devem ser prioridades para revelar detalhes que fogem à primeira vista. Para pesquisas futuras, é prescindível que haja uma conversa entre o discurso dos atores desses mercados populares e a gestão pública, com o intuito de promover ajuste das políticas públicas, procurando soluções benéficas para o desenvolvimento da cidade, dos vendedores e clientes. Uma alternativa de pesquisa futura poderia abordar um comparativo resiliente entre os mercados existentes atualmente em uma grande cidade.

\section{REFERÊNCIAS}

ABRIC, Jean-Claude. Pratiques sociales et re- présentations. [S.l. : s.n.], 2003.

ALVES, Lidiane Aparecida; RIBEIRO FILHO, Vitor. Os mercados públicos e a cidade: as transformações do Mercado Municipal de Uberlândia (MG). Caminhos de Geografia, v. 12 , n. 39, 2011.

BAUDRILLARD, Jean. A sociedade de consumo. Rio de Janeiro: Elfos, 1995.

BELK, Russell W. Possessions and the extended self. Journal of consumer research, v. 15, n. 2, p. 139-168, 1988.

BOGDAN, Robert; TAYLOR, Steven J. Introduction to qualitative research methods: A phenomenological approach to the social sciences. [S.l.]: John Wiley \& Sons, 1975.

BRIGUGLIO, Lino et al. Economic vulnerability and resilience: concepts and measurements. Oxford development studies, v. 37, n. 3, p. 229-247, 2009.

BUENO, Newton Paulo. Assessing the resilience of small socio ecological systems based on the dominant polarity of their feedback structure. System Dynamics Review, v. 28, n. 4, p. 351-360, 2012.

BURNARD, Kevin; BHAMRA, Ran. Organisational resilience: development of a conceptual framework for organisational responses. International Journal of Production Research, v. 49, n. 18, p. 5581-5599, 2011.

CARRIERI, A. P.; SARAIVA, L. A.; PIMENTEL, T. D. A institucionalização da Feira Hippie de Belo Horizonte. O\&S. Organizações \& Sociedade, v. 15, n. 44, p. 63-79, 2008.

CARVALHO, Virgínia Donizete de et al. Resiliência e socialização organizacional entre servidores públicos brasileiros e noruegueses. Revista de Administração Contemporânea, v. 15, n. 5, p. 815-833, 2011. 
CAVEDON, N. R. "Pode chegar, freguês": a cultura organizacional do mercado público de Porto Alegre. Organizações \& Sociedade, v. 11, n. 29, p. 173-189, 2004.

CAVEDON, Neusa Rolita et al. "O mate amargo e o doce de leite": entrecruzando as culturas regionais, locais e organizacionais nos Mercados Públicos de Porto Alegre e de Uberlândia. Gestão \& Planejamento-G\&P, v. 11, n. 2, 2011 .

DANTAS, Marcelo. Gestão, cultura e leadership-o caso de três organizações afrobaianas. In: FISCHER, Tânia. Gestão Contemporânea: cidades estratégicas e organizações locais. Rio de Janeiro: FGV, 1996.

FRANCIS, Royce; BEKERA, Behailu. A metric and frameworks for resilience analysis of engineered and infrastructure systems. Reliability Engineering \& System Safety, v. 121, p. $90-103,2014$.

GERHARD, Felipe; PEÑALOZA, Verónica. Resilience in trade fairs: a study in brazilian context. Interações (Campo Grande), v. 19, n. 4, p. 855-869, 2018.

GOMIDE JÚNIOR, Sinésio; SILVESTRIN, Luiz Humberto Bonito; OLIVEIRA, Áurea de Fátima. Bem-estar no trabalho: o impacto das satisfações com os suportes organizacionais e o papel mediador da resiliência no trabalho. Revista Psicologia Organizações e Trabalho, v. 15, n. 1, p. 19-29, 2015.

HAMEL, Gary; VALIKANGAS, Liisa. En busca de la resiliencia. [S.l.: s.n.], 2003.

HERRMAN, Helen et al. What is resilience?. The Canadian Journal of Psychiatry, v. 56, n. 5 , p. $258-265,2011$.

HOLLING, Crawford S. Resilience and stability of ecological systems. Annual review of ecology and systematics, v. 4, n. 1, p. 1-23,
1973.

HOLLING, Crawford S. Understanding the complexity of economic, ecological, and social systems. Ecosystems, v. 4, n. 5, p. 390-405, 2001.

IRIGARAY, Hélio Arthur Reis; PAIVA, Kely Cesar Martins de; GOLDSCHMIDT, Cristina Chaves. Resiliência organizacional: proposição de modelo integrado e agenda de pesquisa. Cadernos Ebape. Br, v. 15, n. SPE, p. 390-408, 2017.

KINJO, Tomoko; IKEDA, Ana. Comportamento do consumidor em feiras livres. CEP, v. 7195, p. 120, 2005.

LEE, Ji Hee et al. Resilience: a meta analytic approach. Journal of Counseling \& Development, v. 91, n. 3, p. 269-279, 2013.

LIPOVETSKY, Gilles. A felicidade paradoxal: ensaio sobre a sociedade de hiperconsumo. São Paulo: Companhia das Letras, 2007.

LUTHANS, Fred et al. Psychological capital development: toward a micro intervention. Journal of Organizational Behavior: The International Journal of Industrial, Occupational and Organizational Psychology and Behavior, v. 27, n. 3, p. 387-393, 2006.

MARCHAND, Pascal; RATINAUD, Pierre. L'analyse de similitude appliquée aux corpus textuels: les primaires socialistes pour l'élection présidentielle française (septembre-octobre 2011). Actes des 11eme Journées internationales d'Analyse statistique des Données Textuelles. JADT, v. 2012, p. 687-699, 2012.

MEDD, Will; MARVIN, Simon. From the politics of urgency to the governance of preparedness: a research agenda on urban vulnerability. Journal of Contingencies and Crisis Management, v. 13, n. 2, p. 44-49, 2005. 
OLAVARRIETA, Sergio; FRIEDMANN, Roberto. Orientação para o mercado, recursos relacionados ao conhecimento e desempenho da empresa. Journal of business research, v. 61, n. 6, p. 623-630, 2008.

OZUDURU, Burcu H.; VAROL, Cigdem; ERCOSKUN, Ozge Yalciner. Do shopping centers abate the resilience of shopping streets? The co-existence of both shopping venues in Ankara, Turkey. Cities, v. 36, p. 145-157, 2014.

PACHECO, Susana Mara Miranda. Resiliência urbana e comercial em áreas centrais. Geo Uerj, v. 2, n. 23, p. 459-478, 2012.

PATON, Douglas; SMITH, Leigh; VIOLANTI, John. Disaster response: risk, vulnerability and resilience. Disaster Prevention and Management: An International Journal, v. 9, n. 3, p. 173-180, 2000.

PERDIGÃO, Denis Alves; CARRIERI, Alexandre de Pádua; SARAIVA, Luiz Alex Silva. Das ruas para os shoppings populares: o empreendedorismo informal no discurso dos camelôs e da Prefeitura de Belo Horizonte. Perspectivas Contemporâneas, v. 9 , n. 1, p. 43-58, 2014.

PEREIRA, Costa. Análise de dados qualitativos aplicados às representações sociais. Psicologia, v. 15, n. 1, p. 177-204, 2001.

PETRESCU, Maria; BHATLI, Dhruv. Consumer behavior in flea markets and marketing to the Bottom of the Pyramid. Journal of Management Research, v. 13, n. 1, p. 55-63, 2013.

PIERRI, M. C. Q. M.; VALENTE, A. L. E. F. A feira livre como canal de comercialização de produtos da agricultura familiar. $I n$ : $\mathrm{CON}-$ GRESSO DA SOBER, 48., 2010, Campo Grande. Anais [...]. Campo Grande: Sober, 2010.

PIMENTEL, Thiago Duarte et al. From the basílica to the feira... from oasis to Shoppingleu": the path of metaphors of Jubileu in Congonhas (MG). Revista de Administração Pública, v. 45, n. 1, p. 45-66, 2011.

PINTAUDI, Silvana Maria. Os mercados públicos: metamorfoses de um espaço na história urbana. Revista Cidades, v. 3, n. 5, 2006.

RAJAGOPAL, R. Coexistence and conflicts between shopping malls and street markets in growing cities: analysis of shoppers' behavior. Tecnológico de Monterrey, Campus Ciudad de México, 2010.

RUTTER, Michael. Implications of resilience concepts for scientific understanding. Annals of the New York Academy of Sciences, v. 1094, n. 1, p. 1-12, 2006.

SARAIVA, L. A. S.; CARRIERI, A. P.; SOARES, A. S. Territorialidade e identidade nas organizações: o caso do Mercado Central de Belo Horizonte. RAM. Revista de Administração Mackenzie, v. 15, p. 97-126, 2014.

SHERRY JUNIOR, John F. Revendedores e negociando em um mercado periódico: varejo informal em perspectiva etnográfica. Journal of retailing, v. 66, n. 2, p. 174-200, 1990.

SIQUEIRA, Maria de Lourdes. "Agô Agô Lonan": Mitos, Ritos e Organizações em Terreiros de Candomblé na Bahia. In: ENCONTRO DAANPADA, 17., 1993, Salvador. Anais [...]. Salvador: ENANPAD, 1993.

SMITH, Bruce W. et al. The brief resilience scale: assessing the ability to bounce back. International journal of behavioral medicine, v. 15, n. 3, p. 194-200, 2008.

SOUMAGNE, J. et al. Retail planning for cities sustainability (Replacis). Portugal: [s.n.], 2009.

SPRADLEY, James P. Participant Obser- 
vation. Orlando, Florida: Holt, Rinehard and Winston, 1980.

STUMPP, Eva-Maria. New in town? On resilience and "Resilient Cities". Cities, v. 32, p. 164-166, 2013.

VERGARA, Sylvia Constant. Métodos de pesquisa em administração.São Paulo: Atlas, 2005.

VERGÈS, Pierre; BOURICHE, Boumedienne. L'analyse des données par les graphes de similitude. Sciences humaines, p. 1-90, 2001.

WACHELKE, João; WOLTER, Rafael. Criteria related to the realization and reporting of prototypical analysis for social representations. Psicologia: Teoria e Pesquisa, v. 27, n. 4, p. 521-526, 2011.

WALKER, Brian et al. A handful of heuristics and some propositions for understanding resilience in social-ecological systems. Ecology and society, v. 11, n. 1, 2006.

YUNES, Maria Angela Mattar. Psicologia positiva e resiliência: o foco no indivíduo e na família. [S.l.: s.n.], 2003. 